\title{
An Economic Analysis of Small-Scale Standalone Photovoltaic System with Hydrogen Storage System
}

\author{
Nur Dalilah Nordin ${ }^{1}$, Hasimah Abdul Rahman*1 \\ ${ }^{1}$ Centre of Electrical Energy Systems, Institute of Future Energy, Universiti Teknologi Malaysia, 81310 \\ Johor Bahru, Johor, Malaysia \\ *Corresponding author: hasimah@fke.utm.my
}

\author{
Article History \\ Received: March 01, 2018 \\ Received in revised form: May 20, 2018 \\ Accepted: June 06, 2018 \\ Published: July 30, 2018
}

\begin{abstract}
This paper proposes design steps in obtaining the optimal size of a standalone photovoltaic (PV) system, which is able to meet a predetermined power load requirement. The keys of the system sizing are primarily to satisfy a specific load demand that depends on the power generated from the installed PV system and also to maintain hydrogen storage state of charge. A case study was conducted using Kuala Lumpur's meteorological data and a typical rural area load profile of $2.215 \mathrm{kWh}$. An economic analysis on the system was performed in order to determine system feasibility. The levelized cost of energy for the proposed system was RM1.98/kWh. However, the results showed that if the same configuration used absorbent glass mat (AGM) battery as the backup power supply, the system cost and levelized cost of energy is lower. Therefore, a sensitivity analysis of the electrolyzer and fuel cell efficiencies towards levelized cost of energy for the proposed system was executed. The result indicates that unless the efficiency of hydrogen storage technologies significantly increases in the future, the system will not be feasible to be implemented in Malaysia.
\end{abstract}

Keywords: Standalone power system, photovoltaic generation, hydrogen storage, battery, economic analysis.

\subsection{INTRODUCTION}

World's electricity production depends mostly on coal, oil, and natural gas as power supply. Due to limited reserves of fuels, unstable prices, and global warming risks, the interest in renewable energy (RE) sources is increasing significantly. Moreover, the use of RE proves that the dependency on fossil fuels is declining, since RE is environmental friendly, free, and abundantly available [1].

Among the alternative energy available in Malaysia, a photovoltaic (PV) system has a big potential for electricity generation. However, because of its variation in nature, a standalone photovoltaic (SAPV) system needs another power source to support the system to continuously supply the power. In most cases, an SAPV system uses a battery as a backup power supply at night or during low irradiation period. A properly designed SAPV with a battery system requires an adequate capacity of PV array and battery, suitable charge controller rating, and inverter rating. There are several technologies of battery suitable for SAPV system application, such as lead-acid battery, lithium-ion battery, flow battery, and nickel-cadmium battery. Lead-acid battery has been employed in RE applications for decades and successfully applied in an off-grid system. Among several types of lead-acid battery, absorbent glass mat, gel, and flooded batteries are the most commonly used [2]. Battery's cycle life depends on its depth of discharge, since the battery degrades as it is charged and discharged, and the discharge-recharge cycle is affected by the maximum depth of discharged. The higher the battery capacity is discharged each time it is used, the faster the battery degrades.

Other than battery, an SAPV system can also use a generator as a backup power supply. A generator is not only implemented as a backup power supply, but it can also be used as a supply for other loads that exceed inverter capacity [3]. However, similar to a battery, a generator is quite expensive, requires maintenance, and has low lifetime compared 
to a PV system. Besides, it also creates noises when running and pollutes the environment.

Past literature also suggested a hybrid SAPV system coupled with other renewable energies, such as wind. A hybrid SAPV system with wind is highly recommended, since both sources are unlimited and can be installed anywhere (depending on site condition). A proper combination is able to overcome the shortcoming of their intermittency and unpredictable nature. However, an SAPV with wind system still needs to install an additional backup power, such as a battery and a generator, in order to provide more security and increase system reliability.

Recently, hydrogen storage system (HSS) has been receiving a lot of attention as an energy storage due to its regenerative hydrogen feature. Integrating PV with HSS leads to non-polluting and reliable energy sources, insightful environmental benefits, and reducing emissions. The introduction of HSS in the energy mix is one of the big steps to introduce hydrogen economy in a small-scale autonomous power application due to the high cost of energy produced by a conventional SAPV generation system.

In an SAPV system, hydrogen is produced from water by electrolysis process in an electrolyzer, powered by the excess electricity from PV generation. An electrolyzer decomposes water molecules into hydrogen and oxygen. The most common or preferable technologies used for water electrolysis are alkaline and proton exchange membrane electrolyzer (PEME). The advantage of PEME technology is that it has high energy efficiency for each stack (75-88\%), whereas an alkaline electrolyzer has lower energy efficiency range (62-74\%) [4]. The hydrogen produced is then stored in a hydrogen tank. When the load demand is higher than the generated PV energy, the stored hydrogen and air are fed into a fuel cell (FC) $[5,6]$. Fuel cell is widely used to convert pure hydrogen into usable energy. It performs a reverse electrochemical reaction in the electrolyzer, which converts hydrogen and oxygen to produce energy and water.

This paper presents an economic analysis of a small-scale SAPV system with HSS for a predefined residential load demand. A case study was conducted using Kuala Lumpur's meteorological data and typical rural area daily load profile of $2.215 \mathrm{kWh}$. Detail configuration, system sizing, and economic analysis were performed and also discussed. Finally, the levelized cost of energy (LCOE) of the proposed system was determined. The new concept in this contribution introduces the integration of PV with HSS, with prior information, assessment, and extensive sizing steps on each component with respect to the site's local environment (or climate condition). It is important so that it meets the design requirement of the plant installation (load demand). An economic analysis was carried to determine the system feasibility and economically utilize the PV and HSS system [7, 8].

\subsection{SYSTEM CONFIGURATION}

The proposed configuration for an SAPV system with HSS in Malaysia is shown in Fig. 1. During daytime, the PV system generates DC power. If a PV array produces higher power than load demand, the surplus power goes to an electrolyzer. The electrolyzer uses the excess power to convert water into hydrogen and oxygen. The hydrogen is stored in a hydrogen tank and oxygen is released into the air. However, during insufficient PV power, FC draws hydrogen from the storage tank and oxygen from the air, and converts both gases into water again to produce more power to serve load demand. Meanwhile, an inverter is used to convert DC power into AC power [9, 10].

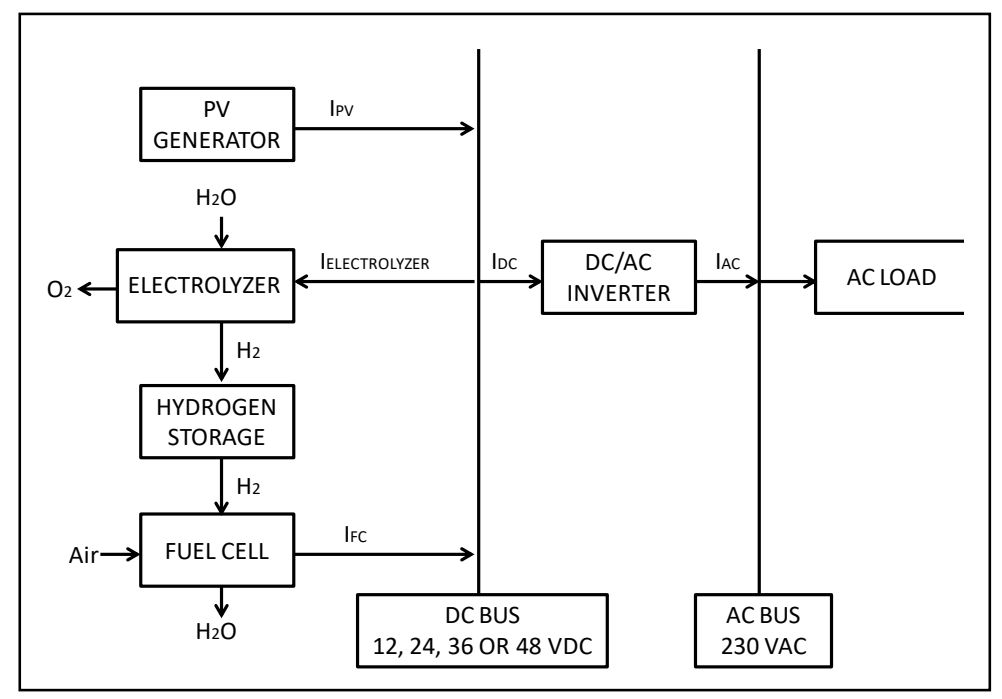

Figure 1. System configuration for an SAPV system with HSS [9, 10] 
Predicting PV accuracy has a great importance in sizing process. This is because the energy generated by a PV system is forecasted from the site's weather data [11]. The average monthly annual irradiation and PSH data for Kuala Lumpur were generated by Meteonorm 6.1 as shown in Table 1 [12]. It was observed that the annual global irradiation for Kuala Lumpur was $1,655.59 \mathrm{kWh} / \mathrm{m}^{2}$, the maximum average annual irradiance over a year, $H_{\operatorname{Smax}}$ was $205.511 \mathrm{~W} / \mathrm{m}^{2}(\mathrm{March})$, and the lowest monthly daily's peak sun hour, $P S H_{\text {lowest }}$ was $4.081 \mathrm{hr} /$ day (December).

Table 1. Monthly average annual irradiation and daily's peak sun hour in Kuala Lumpur [12]

\begin{tabular}{|c|c|c|c|c|c|}
\hline Month & Average Annual Irradiance $\left(\mathbf{W} / \mathbf{m}^{\mathbf{2}}\right)$ & PSH $(\mathbf{h r})$ & Month & Average Annual Irradiance (W/m $\left.\mathbf{m}^{\mathbf{2}}\right)$ & PSH $(\mathbf{h r})$ \\
\hline January & 179.839 & 4.319 & July & 188.978 & 4.535 \\
\hline February & 202.976 & 4.871 & August & 186.962 & 4.487 \\
\hline March & 205.511 & 4.945 & September & 187.778 & 4.513 \\
\hline April & 199.861 & 4.800 & October & 190.860 & 4.584 \\
\hline May & 194.892 & 4.681 & November & 171.944 & 4.127 \\
\hline June & 187.639 & 4.513 & December & 170.027 & 4.081 \\
\hline
\end{tabular}

\subsection{Load Demand}

Table 2 presents the residential load demand in Malaysia's rural area. It is assumed that the daily load remains the same throughout the year [13]. The AC load profile of $2.215 \mathrm{kWh}$ consists of different types of home appliances.

Table 2. Common daily load profile for a house in a rural area

\begin{tabular}{|c|c|c|c|c|}
\hline Appliance & Voltage (V) & Power (W) & Daily Usage (hr) & Energy (Wh) \\
\hline Lamp 1 & 230 & 20 & 10 & 200 \\
\hline Lamp 2 & 230 & 40 & 4 & 160 \\
\hline Television & 230 & 60 & 5 & 300 \\
\hline Refrigerator & 230 & 50 & 24 & 1200 \\
\hline Radio & 230 & 10 & 11 & 110 \\
\hline Ceiling Fan & 230 & 60 & 2 & 120 \\
\hline Desk Fan & 230 & 25 & 5 & 125 \\
\hline Total & & 265 & & 2,215 \\
\hline
\end{tabular}

\subsection{SYSTEM DESIGN}

This section explains the design steps and the calculation needed to determine the required capacity for SAPV components by using amp-hour analysis. The advantage of amp-hour analysis is it considers the actual components' behavior [14].

\section{1 $\quad$ Estimation of Load Profile}

First, the total daily energy requirement was estimated. All AC equipment including their rated power and the total usage in hours per day was listed. After that, the daily AC load demand, $E_{A C}$ was determined. Additional energy was also considered to cover losses by components' inefficiencies. The estimation of energy losses and total daily energy requirement was calculated by using Equation 1 and $2\left(\eta_{\text {AClosses }}=0.35\right)$ [14]. The daily system charge requirement, $Q_{\text {req }}$ (Ah) was calculated using Equation 3, where $V_{D C b u s}$ is the DC bus voltage.

$$
\begin{gathered}
A C_{\text {losses }}=E_{A C} * \eta_{A C_{\text {losses }}} \\
E_{\text {req }}=E_{A C}+A C_{\text {losses }} \\
Q_{r e q}=\frac{E_{r e q}}{V_{D C_{\text {bus }}}}
\end{gathered}
$$


In sizing of PV arrays, designers have to estimate site's meteorological data. Sizing calculation by using the lowest monthly PSH (hr), $P S H_{\text {lowest }}$, actually prevents the system to be undersized. The array sizing needs to be aligned with the load demand. Hence, from the value obtained from Equation 3, $Q_{\text {req }}(\mathrm{Ah})$, the system charging current by PV array, $I_{\text {charge }}$ (A) was determined by Equation 4 [14].

$$
I_{\text {charge }}=\frac{Q_{\text {req }}}{\text { PSH }_{\text {lowest }}}
$$

The modules connection was arranged based on the preselect PV model's technical data [15]. Equation 5 was used to determine the number of parallel string, $N_{p}$, where $I_{m p}$ is the PV current maximum power. Next, series-connected panels in each parallel string, $N_{\text {mod/strg }}$, were calculated by Equation 6, where $V_{\text {mod_rated }}$ is the PV rated voltage. Lastly, the total PV modules, $N_{p v}$ were determined by Equation 7 [14]:

$$
\begin{gathered}
N_{p}=\text { roundup }\left(\frac{I_{\text {charge }}}{I_{m p}}\right) \\
N_{\text {mod } / \text { strg }}=\frac{V_{\text {od_rated }}}{V_{D C_{\text {bus }}}} \\
N_{p v}=N_{p} * N_{\text {mod } / \text { strg }}
\end{gathered}
$$

\subsection{Sizing of Proton Exchange Membrane Electrolyzer}

The preferable and most common technologies used in water electrolyzers are alkaline and PEME. Commercially available PEME can produce from 400-7,900 kg of hydrogen each year with pressure generation up to 13.8 bar. Meanwhile, an alkaline electrolyzer produces $2400-71,000 \mathrm{~kg}$ of hydrogen over a year. The advantage of PEME technology is it has high energy efficiency for each stack (75-88\%) with 5\% as the minimum required output flow for a safe operation [4].

An electrolyzer decomposes water into hydrogen and oxygen by passing electrical current (i.e. DC) between two electrodes separated by an aqueous electrolyte with good ionic conductivity. The reactions take place at the anode and the cathode of an electrolyzer are as follows [16]:

Anode:

$$
\mathrm{H}_{2} \mathrm{O} \rightarrow \frac{1}{2} \mathrm{O}_{2}+2 \mathrm{H}^{+}+2 e^{-}
$$

Cathode:

$$
2 H^{+}+2 e^{-} \rightarrow H_{2}
$$

The storage charge capacity required, $Q_{\text {stored }}$ was determined by Equation $10[14,17]$, where $N_{c}$ is the number of reserved days and $D O D$ is the depth of discharge. $N_{c}$ was set between 1 and 4 days, and it is recommended that DOD should not be more than $60 \%$. Energy storage consumption, $E_{\text {storeq }}$ is the amount of energy consumed to produce stored hydrogen and was calculated using Equation 11 , where $\eta_{E l z}$ is the electrolyzer efficiency and $\eta_{F C}$ is the FC efficiency $\left(\eta_{E l z}=0.88\right.$ and $\left.\eta_{F C}=0.6\right)$.

$$
\begin{gathered}
Q_{\text {stored }}=\frac{Q_{\text {req }} * N_{C}}{D O D} \\
E_{\text {stored }}=\frac{Q_{\text {stored }} * V_{D C_{\text {bus }}}}{\eta_{E l z^{*}} \eta_{F C}}
\end{gathered}
$$


Meanwhile, the electrolyzer rated power, $P_{E l z}$ is equal to the maximum excess in the PV generation power over the minimum load power, where $A_{P V}$ is the PV panel area and $\eta_{P V}$ is the PV panel efficiency $[4,18]$.

$$
P_{E l z}=H_{\text {Smax }} * A_{P V} * \eta_{P V}
$$

\subsection{Sizing of $\mathrm{H}_{2}$ Storage Tank}

Hydrogen can be stored in liquid or gas condition. Liquid hydrogen is stored in cryogenic tanks and gaseous hydrogen is stored in either medium or high-pressure cylinders or near atmospheric pressure in metal hydrides. The hydrogen formed by the electrolyzer during each month is calculated by assuming the produced hydrogen is stored completely before it supplies power to the residential load. The amount of hydrogen produced annually is the total excess of PV power transformed into volume, which is expressed in $\mathrm{m}^{3}$ [18].

Equation 13 represents the hydrogen mass required to produce the specific electrical energy, $m_{h 2}$ where $H H V$ is the higher heating value of hydrogen $(39.44 \mathrm{kWh} / \mathrm{kg})$. The hydrogen's required volume capacity, $V_{h 2}$ was calculated in the next equation, where $M_{c}$ is the margin coefficient for a compressor and storage hydrogen leakage compensation, and $\rho_{h 2}$ is the hydrogen density. The value of $M_{c}$ is greater than 1.1 and $\rho_{h 2}$ is $0.089 \mathrm{~kg} / \mathrm{m}^{2}$ [4].

$$
\begin{aligned}
& m_{h_{2}}=\frac{E_{\text {stored }}}{H H V} \\
& V_{h_{2}}=\frac{m_{h_{2}}}{M_{c^{*} \rho_{h_{2}}}}
\end{aligned}
$$

\subsection{Sizing of Proton Exchange Membrane Fuel Cell}

The reverse reaction occurs in an electrolyzer takes place in FC. Hydrogen in the anode is ionized, releasing electrons and protons. Electrons flow to the cathode through a circuit, producing electric current. Protons diffuse through a polymer electrolyte membrane and react at the cathode with oxygen and electrons to form water. The chemical reactions happened in a proton exchange membrane fuel cell (PEMFC) as below [16]:

Anode:

$$
H_{2} \rightarrow 2 H^{+}+2 e^{-}
$$

Cathode:

$$
\frac{1}{2} \mathrm{O}_{2}+2 \mathrm{H}^{+}+2 e^{-} \rightarrow \mathrm{H}_{2} \mathrm{O}
$$

The following equation is for FC sizing by considering the maximum AC load power in the household, where $M_{F C}$ is the margin coefficient of FC, $P_{\text {ACload }}$ is the total AC load power, and $\eta_{i n v}$ is the inverter efficiency [18].

$$
P_{F C}=M_{F C} * \frac{P_{A C l o a d}}{\eta_{\text {inv }}}
$$

\subsection{Sizing of Inverter}

An inverter is supposed to convert DC supply and fulfill the maximum AC load in a household. Hence, inverter power rating, $P_{i n v}$ was determined using Equation 18, where 1.25 is an oversized factor [19].

$$
P_{\text {inv }}=P_{\text {ACload }} * 1.25
$$




\subsection{ECONOMIC ANALYSIS}

Economic analysis determines the viability of the proposed system. In this paper, life-cycle cost (LCC) and LCOE were used to analyze the feasibility of the system. LCC is the present value of installation cost, operating and maintenance cost, and replacement cost [20]. Equation 19 presents LCC equation, where $C_{p v}$ is the solar array cost, $C_{\text {storage }}$ is the HSS cost, $C_{i n v}$ is the inverter cost, $C_{\text {install }}$ is the installation cost, $C_{\text {invrep }}$ is the present value of inverter replacement, $C_{O \& M_{-} 20 y e a r s}$ is the present value of operation and maintenance cost ( $1 \%$ from the initial cost), and $C_{\text {salvage }}$ is the salvage value ( $20 \%$ from the initial cost). All components have 20 years of lifetime, besides the inverter (inverter lifetime $=10$ years) [21, 22]. $N$ is the project's period and $i$ is the market rate.

$$
\begin{gathered}
\text { LCC }=C_{p v}+C_{i n v}+C_{\text {controller }}+C_{\text {install }}+C_{\text {invrep }}+C_{\text {O\&M_20years }}+C_{\text {salvage }} \\
C_{\text {invrep }}=C_{\text {inv }}\left(\frac{i}{1+i}\right)^{N} \\
C_{O \& M_{-} 20 y e a r s}=C_{O \& M} *\left[\frac{\left(\frac{i}{1+i}\right)^{N}-1}{i *\left(\frac{i}{1+i}\right)^{N}}\right]
\end{gathered}
$$

Market interest rate, $i$ was determined using Equation 22, where $i$ ' is the real interest rates. $i$ ' was calculated using Equation 23 [23], where $B L B$ is the base lending rates, and $\bar{f}$ is the inflation rate $[24,25]$.

$$
\begin{gathered}
i=i^{\prime}+\bar{f}-i^{\prime} * \bar{f} \\
i^{\prime}=B L B-2 \%
\end{gathered}
$$

LCOE $(\mathrm{RM} / \mathrm{kWh})$ is the average cost per $\mathrm{kWh}$ of electrical energy produced by a PV array [26]. It was calculated by dividing annualized life-cycle cost, $L C C_{\text {lyear }}$ with the total useful electrical energy generated, $E_{P V}$, as calculated by the following equations [27]. Table 3 summarizes the market prices for the system components [4, 8,22, 28-31].

$$
\begin{gathered}
L C C_{1 y e a r}=\frac{L C C}{\left[\frac{\left(\frac{i}{1+i}\right)^{N}-1}{\left.i *\left(\frac{i}{1+i}\right)^{N}\right]}\right.} \\
L C O E=\frac{L C C_{1 y e a r}}{E_{p v}} \\
E_{p v}=N_{p v} * P_{m p_{-} S T C} * P S H_{\text {year }} * \eta_{\text {losses }}
\end{gathered}
$$

Table 3. Pricing of components $[4,8,22,28-31]$

\begin{tabular}{|c|c|c|}
\hline Components & Unit & RM \\
\hline Solar Panel, 140 W & 1 & 886.17 \\
\hline Inverter, 340 W & 1 & 560.71 \\
\hline PEME & $\mathrm{RM} / \mathrm{W}$ & 4.44 \\
\hline $\mathrm{H}_{2}$ Storage Tank & $\mathrm{RM} / \mathrm{Nm}^{3}$ & 77.88 \\
\hline PEMFC & $\mathrm{RM} / \mathrm{W}$ & 1.02 \\
\hline Support Structure \& Installation Cost & $\mathrm{RM} / \mathrm{Wp}$ & 4.00 \\
\hline
\end{tabular}




\subsection{RESULTS AND DISCUSSION}

This section presents the system sizing results, economic analysis for 20 years period, feasibility comparison between SAPV with HSS and SAPV with absorbent glass mat (AGM) battery, and sensitivity analysis of LCOE value for SAPV with HSS towards $\eta_{e l z}$ and $\eta_{f c}$ values.

\subsection{Sizing Results}

Table 4 below shows the results of system sizing and each component's technical data. A combination of $1.12 \mathrm{kWh}$ PV modules, 335.4 W PEME, 324.3 $\mathrm{Nm}^{3} \mathrm{H}_{2}$ tank, 285.0 W PEMFC, and $340 \mathrm{~W}$ inverter were chosen as the proposed system.

Table 4. Proposed system sizing

\begin{tabular}{|c|c|c|}
\hline \multicolumn{3}{|c|}{ Daily Energy Requirement } \\
\hline Total Daily AC Energy Demand & $2,215.00$ & Wh \\
\hline AC Losses & 775.25 & $\mathrm{Wh}$ \\
\hline Total Daily Energy Required & $2,990.25$ & Wh \\
\hline System Voltage & 24.00 & VDC \\
\hline Daily Charge Required & 124.59 & $\mathrm{Ah}$ \\
\hline \multicolumn{3}{|c|}{ Sizing of PV Modules } \\
\hline Lowest Daily's Peak Sun Hour & 4.08 & $\mathrm{hr}$ \\
\hline System Design Charging Current & 30.53 & Amp \\
\hline Model & \multicolumn{2}{|c|}{ Kyocera KD140 } \\
\hline Peak Watts & 140.00 & $\mathrm{Wp}$ \\
\hline Rated Voltage & 12.00 & VDC \\
\hline Maximum Power Rated Current & 7.91 & Amp \\
\hline Short Circuit Current & 8.68 & Amp \\
\hline PV Efficiency & 20.40 & $\%$ \\
\hline Number of Parallel String & 4 & \\
\hline Number of Modules/String & 2 & \\
\hline Number of Modules & 8 & \\
\hline PV Array Area & 8.016 & $\mathrm{~m}^{2}$ \\
\hline \multicolumn{3}{|c|}{ Sizing of Hydrogen Storage System } \\
\hline Daily System Charge Requirement & 124.59 & $\mathrm{Ah}$ \\
\hline Reserve Days & 2 & day \\
\hline Maximum DOD & 50 & $\%$ \\
\hline Required System Storage Capacity & 498.38 & $\mathrm{Ah}$ \\
\hline Energy Storage of Electrolyzer & $22,653.4$ & $\mathrm{Wh}$ \\
\hline Rated Power of Electrolyzer & 335.409 & $\mathrm{~W}$ \\
\hline Mass of Hydrogen Stored & 5.63463 & $\mathrm{~N}$ \\
\hline Volume of Hydrogen Stored & 57.555 & $\mathrm{~m}^{3}$ \\
\hline Hydrogen Tank Capacity & 324.301 & $\mathrm{Nm}^{3}$ \\
\hline Rated Power of Fuel Cell & 284.946 & $\mathrm{~W}$ \\
\hline \multicolumn{3}{|c|}{ Sizing of Inverter } \\
\hline Maximum Power AC Load & 265 & $\mathrm{~W}$ \\
\hline Inverter Rating & 340 & $\mathrm{~W}$ \\
\hline Model & \multicolumn{2}{|c|}{ Cotek SK350-224 } \\
\hline Rated Voltage & $24 / 230$ & VDC/VAC \\
\hline Rated Power & 350 & $\mathrm{~W}$ \\
\hline Inverter Efficiency & 93 & $\%$ \\
\hline
\end{tabular}




\subsection{Economic Analysis}

Table 5 below presents the economic analysis for the proposed configuration. From the analysis, the total initial cost for equipment, installation, and structure was RM39,559.79. The present values of operation \& maintenance and replacement cost were RM3,884.06 and RM259.72, respectively. The approximated salvage value was RM7,911.96. Hence, LCC for 20 years was RM35,791.61, and $\mathrm{LCC}_{1 \text { year }}$ was RM3,645.46. $E_{P V}$ for the proposed system was 1,828.305 kWh. Consequently, LCOE calculated was RM1.98/kWh.

Table 5. Economic analysis

\begin{tabular}{|c|c|}
\hline Discount/Interest Rates & $4.60 \%$ \\
\hline Inflation Rates & $3.40 \%$ \\
\hline Net Discount Rates, $i$ & $8.00 \%$ \\
\hline Components & RM \\
\hline \multicolumn{2}{|l|}{ Initial Cost } \\
\hline PV Module(s) & $7,089.36$ \\
\hline Electrolyzer & $1,489.40$ \\
\hline $\mathrm{H}_{2}$ Storage Tank & $11,225.17$ \\
\hline PEMF & 292.00 \\
\hline Inverter & 560.71 \\
\hline Module Support Structure \& System Installation & $4,480.00$ \\
\hline Contingencies & 391.69 \\
\hline Total Initial Cost & $39,559.79$ \\
\hline \multicolumn{2}{|l|}{ O\&M Cost } \\
\hline LCC O\&M $\mathrm{M}_{\mathrm{m}}$ & 395.60 \\
\hline Total Operation \& Maintenance & $3,884.06$ \\
\hline \multicolumn{2}{|l|}{ Replacement Cost } \\
\hline LCC Inverter $_{n 1}$ (Replacement after 10 years) & 259.72 \\
\hline Total Replacement Cost & 259.72 \\
\hline \multicolumn{2}{|l|}{ Salvage } \\
\hline Total Salvage Value & $7,911.96$ \\
\hline \multicolumn{2}{|l|}{$\underline{\text { Result }}$} \\
\hline LCC Cost for 20 Years & $35,791.61$ \\
\hline LCC Cost/Year & $3,645.46$ \\
\hline Cost of Energy (RM/kWh) & 1.98 \\
\hline
\end{tabular}

\subsection{Comparison with Standalone Photovoltaic/Absorbent Glass Mat Battery System Sizing}

The current results were compared with the findings from an SAPV system with AGM battery, which was published in 2014 [28]. Table 6 shows the comparison of the current findings with the published results. From the published literature, the initial cost for the SAPV system with AGM battery was RM39,559.79, the LCC value was RM34,232, the LCC 1 year was RM3,206.82, and the system's LCOE was RM1.76/kWh.

From the comparison, it can be seen that the initial cost, the LCC, the annual LCC, and the LCOE for SAPV with HSS have higher expenditure compared to the published findings [28]. The LCOE for SAPV with HSS was higher by $12.5 \%$. This is because the initial cost needed for HSS is very high as FC efficiency is quite low (60\%). Consequently, bigger HSS capacity is needed to have backup energy similar with an AGM battery during insufficient PV generation.

However, SAPV with AGM battery has a flaw. The AGM battery needs to be replaced every 5 years. Meanwhile, PEME, $\mathrm{H}_{2}$ tank, and PEMFC do not have to be replaced because the lifetime is longer, which is 20 years [18]. Hence, SAPV with HSS could be compatible with SAPV with AGM battery if $\eta_{e l z}$ and $\eta_{f c}$ values increase in the future. 
Table 6. Comparison of SAPV with HSS and SAPV with AGM battery

\begin{tabular}{|c|c|c|}
\hline Economic Analysis Results & SAPV with Hydrogen Storage & SAPV with AGM Battery [9] \\
\hline Initial Cost (RM) & $39,559.79$ & $21,393.75$ \\
\hline LCC Cost for 25 Years (RM) & $35,791.61$ & $34,231.98$ \\
\hline LCC Cost/Year (RM/year) & $3,645.46$ & $3,206.81$ \\
\hline LCOE (RM/kWh) & 1.98 & 1.76 \\
\hline LCOE Percentage Difference & Increased by 12.5\% & \\
\hline
\end{tabular}

\subsection{Sensitivity Analysis}

The sensitivity of LCOE value for SAPV with HSS depends on $\eta_{e l z}$ and $\eta_{f c}$. The effect of $\eta_{e l z}$ and $\eta_{f c}$ values for a range between 0.75 and 1.00 , and 0.50 and 1.00 towards system's LCOE was analyzed. The sensitivity analysis is portrayed in Fig. 2 below.

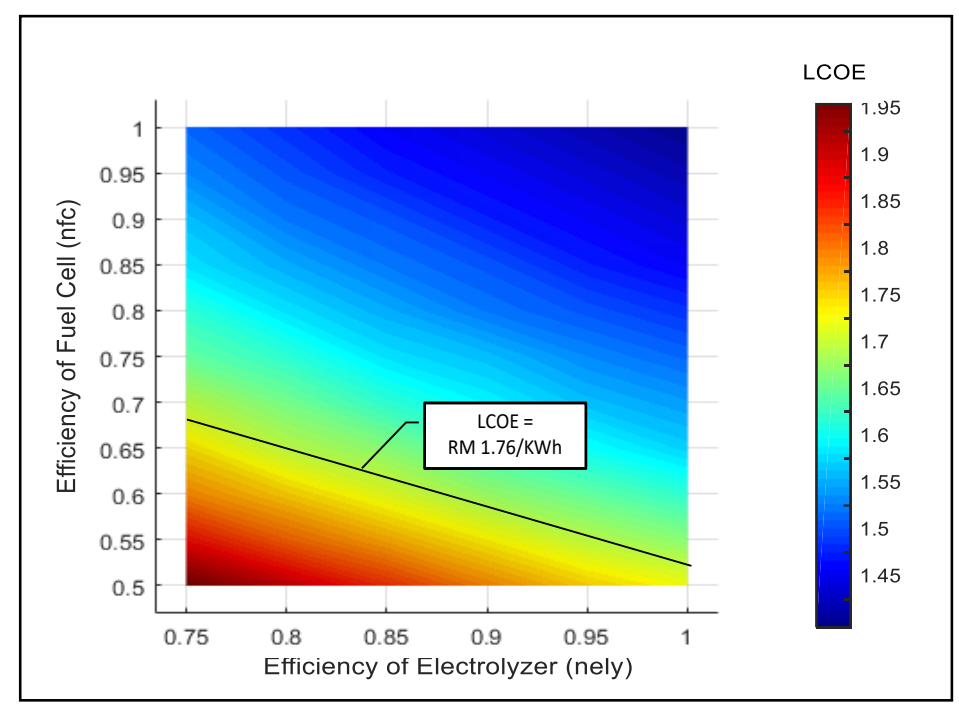

Figure 2. Effect of $\eta_{e l z}$ and $\eta_{f c}$ on LCOE value for SAPV with HSS

The figure above presents a curve of $\eta_{e l z}$ and $\eta_{f c}$ combination and its effect on LCOE value for SAPV with HSS. Based on the figure, for a specific LCOE value (e.g. RM1.76/kWh), the relation between $\eta_{e l z}$ and $\eta_{f c}$ is approximately linear and can be presented by Equation 27 below:

$$
\eta_{f c}=(-0.627) * \eta_{e l y}+1.149
$$

The graph curve and the equation above can be used as references or benchmarks to find the combination of $\eta_{e l z}$ and $\eta_{f c}$ with LCOE value lower than SAPV with AGM battery. The mitigation of $\eta_{e l z}$ and $\eta_{f c}$ value is important, so that an SAPV system with HSS can compete with the conventional SAPV system with AGM in the future.

\subsection{CONCLUSION}

A sizing and economic analysis of a small-scale SAPV with HSS was carried out. Based on the economic assessment, it was found that the LCC for the proposed system, the annual LCC, and the LCOE value obtained were RM35,791.61, RM3,645.46, and RM1.98/kWh, respectively.

However, compared to the economic analysis of SAPV with AGM battery from a published literature [28], the expenditure for the system was lower, where the LCC for the system was RM34,232 and the annual LCC was RM3,206.82. The LCOE value for the SAPV system with AGM battery was lower than the proposed system by $12.5 \%$, which was RM1.76/kWh. It can be seen that even though hydrogen has high energy density per mass, it has low efficiency 
as a storage system and expensive. Due to the low efficiency storage, designers need to store hydrogen storage's energy capacity higher than the AGM battery. However, as an emerging commercialize product, the manufacturers and researchers can focus on how to increase storage system efficiency for future usage. The HSS round-up trip efficiency must improve dramatically before they can offer the same overall energy efficiency as batteries.

Therefore, a sensitivity analysis was performed to find a reference or benchmark value of an electrolyzer and FC efficiencies with the LCOE value lower than SAPV with AGM battery. In order to obtain the LCOE lower than SAPV with AGM battery, a curve and an equation were developed to present the relation between $\eta_{e l z}$ and $\eta_{f c}$ for a predefined LCOE value (RM1.76/kWh). This finding is crucial to envisage the applicability of SAPV with HSS for future power generation in Malaysia.

\section{Acknowledgements}

The authors wish to acknowledge the support for this research paper received from the Malaysian Ministry of Higher Education (MOHE) and Universiti Teknologi Malaysia through the Research University Grant (GUP) vote no: Q.J130000.2523.14H02.

\section{References}

[1] A. Mellit and S. A. Kalogirou. 2008. Artificial intelligence techniques for photovoltaic applications: A review. in Progress in Energy and Combustion Science vol. 34. ed. 574-632.

[2] K. Zipp. (2015, 19 May). Batteries: Which is best for solar storage? Available: https://www.solarpowerworldonline.com/2015/08/what-isthe-best-type-of-battery-for-solar-storage/

[3] (2014, 19 May). Including a Generator With Your Solar Array. Available: https://straightupsolar.com/expertise/backup-generator/

[4] H. Tebibel and S. Labed. 2014. Design and sizing of stand-alone photovoltaic hydrogen system for HCNG production. in International Journal of Hydrogen Energy vol. 39. ed. 3625-3636.

[5] M. Castañeda, A. Cano, F. Jurado, H. Sánchez and L. M. Fernández. 2013. Sizing optimization, dynamic modeling and energy management strategies of a stand-alone PV/hydrogen/battery-based hybrid system. in International Journal of Hydrogen Energy vol. 38. ed. $3830-3845$.

[6] M. A. Pellow, C. J. Emmott, C. J. Barnhart and S. M. Benson. 2015. Hydrogen or batteries for grid storage? A net energy analysis. in Energy \& Environmental Science. ed.

[7] W. Zhou, C. Lou, Z. Li, L. Lu and H. Yang. 2010. Current status of research on optimum sizing of stand-alone hybrid solar-wind power generation systems. in Applied Energy vol. 87. ed. 380-389.

[8] N. Barsoum and P. Vacent. 2007. Balancing cost, operation and performance in integrated hydrogen hybrid energy system. in Modelling \& Simulation, 2007. AMS'07. First Asia International Conference on. ed: IEEE. 14-18.

[9] N. D. Nordin and H. A. Rahman. 2014. Design and economic analysis in stand alone photovoltaic system. in Energy Conversion (CENCON), 2014 IEEE Conference on. ed: IEEE. 152-157.

[10] N. Nordin and H. Rahman. 2017. Sizing and economic analysis of stand alone photovoltaic system with hydrogen storage. in IOP Conference Series: Earth and Environmental Science vol. 93. ed: IOP Publishing. 012068.

[11] D. L. King, W. E. Boyson and J. A. Kratochvil. 2002. Analysis of factors influencing the annual energy production of photovoltaic systems. in Photovoltaic Specialists Conference, 2002. Conference Record of the Twenty-Ninth IEEE. ed: IEEE. 1356-1361.

[12] (23rd February ). PVsyst: Software for Photovoltaic System. Available: http://www.pvsyst.com/en/

[13] W. Shen. 2009. Optimally sizing of solar array and battery in a standalone photovoltaic system in Malaysia. in Renewable Energy vol. 34. ed. 348-352.

[14] M. Hankins. 2010.Stand-alone Solar Electric Systems: The Earthscan Expert Handbook for Planning, Design and Installation: Earthscan.

[15] (20 May 2014). PV Modules in a String. Available: https://nationalvetcontent.edu.au/alfresco/d/d/workspace/SpacesStore/4e1e0e97-bc554c44-a692-4d31f4d0d934/13_02/content_sections/learn_about/08_solar_page_010.htm

[16] D. Ipsakis, S. Voutetakis, P. Seferlis, F. Stergiopoulos and C. Elmasides. 2009. Power management strategies for a stand-alone power system using renewable energy sources and hydrogen storage. in international journal of hydrogen energy vol. 34. ed. 7081-7095.

[17] A. Nafeh. 2009. Design and Economic Analysis of a stand-alone PV system to electrify a remote area household in Egypt. in Open Renewable Energy Journal vol. 2. ed. 33-37. 
[18] R. Jallouli and L. Krichen. 2012. Sizing, techno-economic and generation management analysis of a stand alone photovoltaic power unit including storage devices. in Energy vol. 40. ed. 196-209.

[19] S. I. Sulaiman, T. K. A. Rahman, I. Musirin and S. Shaari. 2011. Sizing grid-connected photovoltaic system using genetic algorithm. in Industrial Electronics and Applications (ISIEA), 2011 IEEE Symposium on. ed: IEEE. 505-509.

[20] V. Applasamy. 2011. Cost evaluation of a stand-alone residential photovoltaic power system in Malaysia. in Business, Engineering and Industrial Applications (ISBEIA), 2011 IEEE Symposium on. ed: IEEE. 214-218.

[21] W. G. Sullivan, E. M. Wicks and J. T. Luxhoj. 2009.Engineering economy: Pearson Prentice Hall.

[22] E. Zoulias and N. Lymberopoulos. 2007. Techno-economic analysis of the integration of hydrogen energy technologies in renewable energybased stand-alone power systems. in Renewable Energy vol. 32. ed. 680-696.

[23] C. S. Park, P. Kumar and N. Kumar. 2004.Fundamentals of engineering economics: Pearson/Prentice Hall.

[24] (1 December 2014). Malaysia Inflation Rate. Available: http://www.tradingeconomics.com/malaysia/inflation-cpi

[25] (1 December 2014). Bank Lending Rates. Available: http://www.blr.my/

[26] S. Kamel and C. Dahl. 2005. The economics of hybrid power systems for sustainable desert agriculture in Egypt. in Energy vol. 30. ed. 12711281

[27] D. Näsvall. 2013. Development of a model for physical and economical optimization of distributed PV systems. ed.

[28] (20 May 2014). Sealed-AGM Batteries. Available: http://www.wholesalesolar.com/products.folder/batteryfolder/Surretterolls.html\#SealedAGMBatteries

[29] (20 May 2014). 140 Watt BLACK FRAME Solar Panel. Available: http://www.ecodirect.com/Kyocera-KD140GX-LFBS-140-Watt-PVPanel-p/kyocera-kd140gx-lfbs.htm

[30] (20 May 2014). Blue Sky Energy. Available: http://www.blueskyenergyinc.com/pricing/

[31] (20 May 2014). 350 Watt 24 Volt Inverter / Pure Sine Wave. Available: http://www.ecodirect.com/Cotek-SK350-124-350W-24V-Pure-SineInverter-p/cotek-sk350-124.htm 